\title{
O CONFORTO TÉRMICO PARA O ANO DE 2016 NO BAIRRO BANGU, RIO DE JANEIRO (RJ)
}

\author{
Lidiane de Oliveira Lemos ${ }^{(a)}$, Antonio Carlos Oscar Júnior ${ }^{(b)}$ \\ (a) Instituto de Geografia - IGEOG/Universidade do Estado do Rio de Janeiro, lidiane.o.lemos@gmail.com \\ (b) Instituto de Geografia - IGEOG/Universidade do Estado do Rio de Janeiro, antonio.junior@uerj.br
}

Eixo: 3. Climatologia em diferentes níveis escalares: mudanças e variabilidades

\begin{abstract}
Resumo
A avaliação do conforto térmico deve ser práxis no planejamento urbano. Nesse sentido, o referido trabalho objetiva analisar o conforto térmico em Bangu em 2016 por meio do computo da sensação térmica e da percepção da população. Para tal finalidade, utilizou-se dados de temperatura e umidade do ar da Estação de Santa Cruz do AlertaRio. Os registros foram submetidos ao índice de temperatura efetiva (TE) para verificar sua classificação nos padrões de conforto. Também foi feita a aplicação de questionários com intuito de averiguar a percepção da sensação térmica pela população banguense e frequentadores. Os resultados constantataram diferentes classes de conforto térmico na análise anual, sazonal e nos períodos diários, com o predomínio de TE na zona de conforto $(37,40 \%)$, sendo superada quando do somatório das classes de desconforto $(59,78 \%)$. Ressalta-se, portanto, questões a serem resolvidas, sobretudo no verão. Identificou-se também distinções na percepção (48\% muito desconfortável) com os registros.
\end{abstract}

Palavras chave: conforto térmico; percepção; Bangu.

\section{Introdução}

O espaço urbano não é dado. É fruto de constantes sobreposições de modificações ao longo do tempo. Neste processo, em que a natureza primitiva perde espaço para a segunda natureza, isto é, o ambiente construído pelo trabalho social (LOBATO, 1992, p.16), os elementos atmosféricos vão sendo alterados em nível local e microclimático, influênciando o conforto térmico humano.

Segundo Fanger (1972), o conforto térmico expressa uma condição da mente de satisfação com o ambiente térmico. Partindo do entendimento que os corpos e ambientes trocam energias, infere-se que esta satisfação depende de vários fatores, dentre estes ambientais e/ou pessoais.

Monteiro (1976) enfatiza que o conforto térmico reúne as componentes termodinâmica, expressas pelas variáveis climáticas de temperatura, ventilação e umidade do ar. Fazendo uso destas variáveis físicas, a linha climato-ambiental propõe o estabelecimento do estado térmico de um ambiente específico. Já, os fatores pessoais, que leva em consideração o conforto do indivíduo em relação ao ambiente que o envolve, englobam parâmetros fisiológicos que diferenciam-se de acordo com cada indivíduo. Portanto, para o 


\section{OS DESAFIOS DA GEOGRAFIA FÍSICA NA FRONTEIRA DO CONHECIMENTO \\ Instituto de Geociências - Unicamp \\ Campinas - SP \\ 28 de Junho à 02 de Julho de 2017}

estudo do conforto térmico diversos componentes necessitam ser considerados, sendo práxis sua avalição quantitativa combinada com a percepção da população afetada. Trata-se, portanto, de um dos parâmetros fundamentais para a manutenção da qualidade de vida, possuindo influência sobre o comportamento, desempenho do homem em seu cotidiano e na saúde.

Embasado nos órgãos de meteorologia, que destacam o ano de 2016 como o mais quente da história, o artigo justifica-se também, quanto a escolha do estudo em Bangu (Figura 1) pelo bairro apresentar uma suscetibilidade natural a elevadas temperaturas. É considerado um dos mais quentes da cidade do Rio de Janeiro, sendo recorrente matérias jornalísticas abordando sua situação térmica, mesmo em diferentes décadas. Bangu abriga recordes históricos de temperaturas, desde 14 de janeiro de 1984 detinha o registro mais alto da cidade $\left(43,1^{\circ} \mathrm{C}\right)$, ultrapassado por Santa Cruz $\left(43,2^{\circ} \mathrm{C}\right)$ em 26 de dezembro de 2012 , segundo o Instituto Nacional de Meteorologia (INMET).

Assim, o referido trabalho teve como objetivo a análise do conforto térmico para o ano de 2016 no bairro Bangu, localizado na Zona Oeste do Município do Rio de Janeiro, por meio do computo da sensação térmica, classificando segundo os padrões de conforto térmico, e da percepção da população banguense e frequentadores do bairro. Como estratégia metodológica buscou-se unir e comparar os parâmetros meteorológicos e aqueles subjetivos da percepção, buscando a interação entre eles.

\section{Caracterização da área de estudo}

O bairro Bangu, criado em 8 de Março de 1863, encontra-se entre a latitude $22^{\circ} 52^{\prime} 24^{\prime \prime}$ S e longitude $43^{\circ}$ 27 ' 18'W. Localizado na Zona Oeste do Município do Rio de Janeiro, possui extensão territorial de $38.800 .400 \mathrm{~m}^{2}$, com o total de 83.068 domicílios e uma população absoluta de 243.125 habitantes (CENSO, 2010) - o que confere ao bairro o título de segundo mais populoso da cidade.

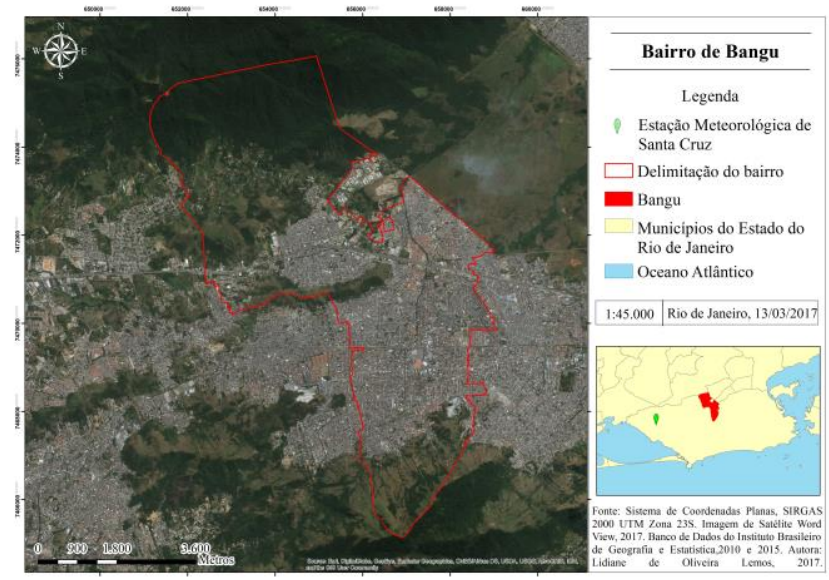

Figura 1 - Localização do bairro Bangu, na cidade do Rio de Janeiro. 


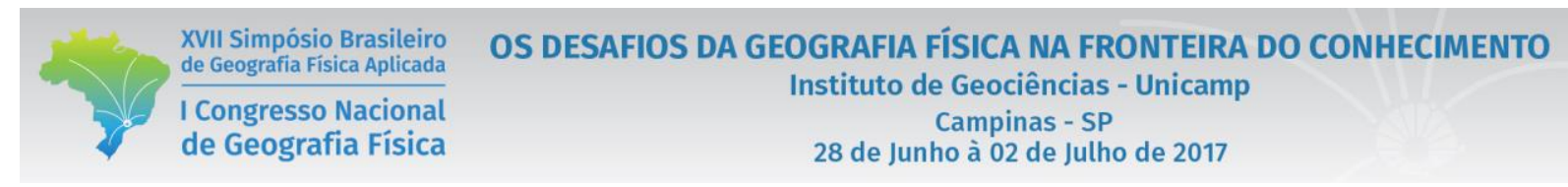

Sua disposição geográfica, em um fundo de vale, entre os maciços do Gericinó, ao norte, e Pedra Branca, ao sul, leva a formação de uma circulação atmosférica local, os ventos fohn, anabático e catabático - o que confere ao bairro uma suscetibilidade natural a elevadas temperaturas. Somado a questão natural, a apropriação do espaço urbano do bairro também se faz sobre as encostas dos maciços, sobretudo o da Pedra Branca, aumentando a degradação sobre a vegetação, reduzindo o processo de evapotranspiração e consequentemente influenciando no desconforto térmico.

Segundo Lemos e Oscar Júnior (2016) os maiores índice de vegetação por diferença normalizada (NDVI ${ }^{1}$ ) intra-bairro estão nas maiores altitudes, onde a vegetação encontra-se mais conservada, sobretudo no maciço do Gericinó, decaindo da encosta até o vale, onde se dá grandes estresses. Por sua vez, as temperaturas da superfície mais elevadas ocorrem onde há predomínio e diversidade de classificações no grupo áreas urbanizadas e menores NDVI. Quanto ao uso e cobertura da terra, o bairro apresenta grande diversidade tanto no uso quanto no estado biofísico da cobertura com 15 classificações distribuídas no grupo das áreas urbanizada e áreas não urbanizadas. Já as encostas possuem o predomínio da orientação voltada para o norte, que no caso do hemisfério sul, são as que recebem maior quantidade de radiação.

\section{Material e método}

Para o desenvolvimento da análise do conforto térmico foram utilizados dados diários com registros de quinze em quinze minutos de temperaturas e umidades relativa do ar adquiridos no sítio eletrônico do Sistema Alerta Rio da Prefeitura do Rio de Janeiro, referente a Estação Meteorológica de Santa Cruz², no período de 2016. Os registros foram organizados no $\mathrm{Excel}^{3}$, onde primeiramente, foi realizada a correção quanto ao horário brasileiro de verão $(\mathrm{HBV})$ e, posteriormente, obteve-se as médias de temperatura e umidade relativa do ar para cada hora dos dias do ano de 2016.

Após esta estapa os dados foram submetidos ao índice de temperatura efetiva (TE) proposto por Missenard (1937) apud Souza et al. (2012), uma versão alternativa ao índice de Thom (1959). A Temperatura efetiva foi obtida por meio da equação abaixo:

$T E=T-0,4 X(T-10) X(1-0,01 U R)$

Onde,

\footnotetext{
${ }^{1}$ NDVI é um índice que varia de -1 a 1 , onde quanto mais próximo do -1 maior é o estresse na cobertura arbórea e presença de solos descobertos; quanto mais próximo do 1 maior é a exuberância da cobertura vegetal.

${ }^{2}$ Estação meteorológica do Alerta Rio próxima à Bangu e atende ao estudo, pois encontra-se no mesmo contexto geomorfológico e urbano do bairro.

${ }^{3}$ Aplicativo registrado da Microsoft Corporation.
} 


\section{OS DESAFIOS DA GEOGRAFIA FÍSICA NA FRONTEIRA DO CONHECIMENTO \\ Instituto de Geociências - Unicamp \\ Campinas - SP \\ 28 de Junho à 02 de Julho de 2017}

$$
\begin{aligned}
& \mathrm{TE} \text { - temperatura efetiva }\left(\mathrm{em}{ }^{\circ} \mathrm{C}\right) ; \\
& \mathrm{T} \text { - temperatura do } \operatorname{ar}\left(\mathrm{em}{ }^{\circ} \mathrm{C}\right) ; \\
& \mathrm{UR} \text { - umidade relativa }(\mathrm{em} \%) \text {. }
\end{aligned}
$$

Alguns dados, ao longo de um dia, apresentaram problemas quanto aos registros de 15 em 15 minutos, o que implicou na impossibilidade de cálculo destas médias horárias e consequentemente nos índices de temperatura efetiva. São as médias horárias das 02:00:00 e 03:00:00 dos dias 02 à 31/01/2016, 02 à 20/02/2016, 16 à 31/10/2016, 02 à 30/11/2016 e 02 à 31/12/2016.

A partir dos resultados de TE que foram calculados, fez-se a classicação quanto ao índice de desconforto, segundo Terjung (1966) apud Farias e Brandão (2006) (Tabela I), utilizando a função "se aninhada" no Excel, para se obter a porcentagem do total de horas de cada mês, períodos sazonais contrastantes (verão e inverno) e matutino (05:00 às 12:00), vespertino (13:00 às 18:00) e noturno (19:00 às 04:00) inseridas em cada intervalo de conforto térmico. A escolha por esta classificação justifica-se pelo uso de Farias e Brandão (2006) em estudo voltado para bairro do Maracanã, também na cidade do Rio de Janeiro, atendendo de forma satisfatória o objetivo proposto. Para a definição do total de horas no verão e inverno, utilizou-se como base das informações o site do Instituto de Atronomia, Geofísica e Ciências Atmosférica do Departamento de Astronomia da Universidade de São Paulo.

Finalmente, complementando a estratégia metodológica, foram aplicados $89^{4}$ questionários no bairro entre os dias 30/11/2016 a 10/02/2017, tomando algumas das áreas mais movimentadas como pontos de referência: Centro de Bangu, Parque Lepoldina, Praça da Guilherme da Silveira, Rua Rio da Prata e adjascências, Catiri, Jardim Progresso, Jardim Bangu e Conjunto João Saldanha. Com as respostas levantou-se as demais informações referente ao bairro e sobretudo sobre a percepção da sensação térmica da população, possibilitando, posteriormente, a comparação destes dados com os registros das TE.

Tabela I - Classificação do índice de desconforto, segundo Terjung (1966).

\begin{tabular}{c|c}
\hline Intervalo do ID $\left({ }^{\circ} \mathrm{C}\right)$ & Níveis de conforto térmico \\
\hline$>30^{\circ} \mathrm{C}$ & Stress térmico \\
$27^{\circ} \mathrm{C}-30^{\circ} \mathrm{C}$ & Desconforto por aquecimento \\
$24^{\circ} \mathrm{C}-27^{\circ} \mathrm{C}$ & Leve desconforto \\
$20^{\circ} \mathrm{C}-24^{\circ} \mathrm{C}$ & Zona de conforto ou neutralidade térmica \\
$18^{\circ} \mathrm{C}-20^{\circ} \mathrm{C}$ & Leve desconforto \\
$15^{\circ} \mathrm{C}-18^{\circ} \mathrm{C}$ & Desconforto por resfriamento \\
$12^{\circ} \mathrm{C}-15^{\circ} \mathrm{C}$ & Resfriamento elevado \\
\hline
\end{tabular}

Fonte: Terjung (1966) apud Farias e Brandão (2006).

\footnotetext{
${ }^{4}$ A aplicação de 89 questionários faz parte da pesquisa voltada ao estudo do campo térmico no bairro de Bangu, que visa aplicar no total de 165 questionários, alcançando estatisticamente a confiança de $80 \%$ e margem de erro de $5 \%$.
} 


\section{OS DESAFIOS DA GEOGRAFIA FÍSICA NA FRONTEIRA DO CONHECIMENTO \\ Instituto de Geociências - Unicamp \\ Campinas - SP \\ 28 de Junho à 02 de Julho de 2017}

\section{Resultados}

\subsection{Registros meteorológicos}

O ano de 2016 apresentou um total de 8.784 horas. Contudo, ao coletar os registros para efetuar as médias para cada hora de temperatura e umidade relativa do ar ao longo das 24 horas de 1 dia durante todo o ano de 2016, alguns dados apresentaram problemas o que implicou em sua não utilização para fins de computo da TE, totalizando ao longo do ano 248 horas (2,82\%). O mês de janeiro apresentou 8,06\%, fevereiro $5,46 \%$, outubro $4,30 \%$, novembro e dezembro $8,06 \%$ de horas não calculadas (Tabela II). Portanto, no ano de 2016, tem-se 8.536 (97,18\%) horas com cálculos de TE classificadas segundo critérios mencionados.

A tabela II demonstra a porcentagem de horas inseridas em diferentes faixas de conforto térmico, com todos os intervalos sendo abarcados ao longo do ano. Os meses de maio, junho, julho, agosto, setembro, outubro e novembro apresentaram maiores quantidades de horas inseridas na faixa da zona de conforto ou neutralidade térmica, com 58,06\%, 34,58\%, 38,58\%, 48,66\%, 63,89\%, 46,24\% e 51,11\%, respectivamente. Por outro lado, em janeiro, fevereiro, março, abril e dezembro, predominaram maiores porcentagem de horas na classe de leve desconforto, com 45,97\%, 46,26\%, 52,42\%, 40,14\% e 32,12\%.

Pode-se considerar o mês de setembro o mais confortável de 2016, em termos de registros meteorológicos, apresentando menores porcentagens de horas nos intervalos que configuram desconforto (desconforto por aquecimento $(2,36 \%)$, leve desconforto $(13,19 \%)$, leve desconforto $(17,64 \%)$ e desconforto por resfriamento $(2,92 \%))$. Já os meses com maiores desconfortos foram fevereiro $(84,1 \%)$, março $(80,78) \%$ e abril (76,25\%). Pequenas porcentagens de horas nos meses de janeiro, fevereiro, março, abril, outubro, novembro e dezembro apresentaram elevados TEs na classe stress térmico. Assim como os meses maio, junho, julho e agosto apresentaram muito baixo TEs, inserindo-se no resfriamento elevado.

No entanto, observando o total das quantidades de horas do ano de 2016, identificamos que a faixa zona de conforto ou neutralidade corresponde a $37,40 \%$, as faixas de desconforto ao calor somam $41,04 \%$ e desconforto ao frio apresentam-se com 18,74\%. Logo, os desconfortos juntos superam a faixa de neutralidade. Além disso, os dados demonstram maior representatividade de períodos de não calor $^{5}$ $(37,40 \%+18,74 \%)$, totalizando $56,14 \%$.

\footnotetext{
${ }^{5}$ Como não calor os autores compreendem aquelas faixas de conforto térmico que não há desconforto ao calor.
} 
XVII Simpósio Brasileiro de Geografia Fisica Aplicada

I Congresso Nacional de Geografia Física

\section{OS DESAFIOS DA GEOGRAFIA FÍSICA NA FRONTEIRA DO CONHECIMENTO Instituto de Geociências - Unicamp \\ Campinas - SP \\ 28 de Junho à 02 de Julho de 2017}

Tabela II - Classificação da porcentagem de horas por mês nas classes de conforto térmico.

\begin{tabular}{|c|c|c|c|c|c|c|c|c|c|c|c|c|c|c|}
\hline Intervalo do $\mathrm{ID}\left({ }^{\circ} \mathrm{C}\right)$ & Níreis de conforto térmico & Janeiro & Ferereiro & Março & Abril & Maio & Junho & Julho & Agosto & Setembro & Outubro & Norembro & Dezembro & Total \\
\hline$>30^{\circ} \mathrm{C}$ & Stress térmico & $2,42 \%$ & $7,47 \%$ & $1,48 \%$ & $0,69 \%$ & - & - & - & - & - & $1,34 \%$ & $0,28 \%$ & $4,03 \%$ & $1,46 \%$ \\
\hline $27^{\circ} \mathrm{C}-30^{\circ} \mathrm{C}$ & Desconforto por aquecimento & $18,15 \%$ & $31,18 \%$ & $26,88 \%$ & $29,58 \%$ & $1,48 \%$ & - & $1,75 \%$ & $2,55 \%$ & $2,36 \%$ & $6,18 \%$ & $8,19 \%$ & $24,87 \%$ & $12,69 \%$ \\
\hline $24^{\circ} \mathrm{C}-27^{\circ} \mathrm{C}$ & Leve desconforto & $45,97 \%$ & $46,26 \%$ & $52,42 \%$ & $40,14 \%$ & $14,92 \%$ & $4,03 \%$ & $11,02 \%$ & $11,69 \%$ & $13,19 \%$ & $24,19 \%$ & $27,22 \%$ & $32,12 \%$ & $26,89 \%$ \\
\hline $20^{\circ} \mathrm{C}-24^{\circ} \mathrm{C}$ & Zona de conforto ou neutralidade térmica & $25,40 \%$ & $9,63 \%$ & $19,22 \%$ & $23,75 \%$ & $58,06 \%$ & $34,58 \%$ & $38,58 \%$ & $48,66 \%$ & $63,89 \%$ & $46,24 \%$ & $51,11 \%$ & $28,63 \%$ & $37,40 \%$ \\
\hline $18^{\circ} \mathrm{C}-20^{\circ} \mathrm{C}$ & Leve desconforto & - & - & - & $5,83 \%$ & $19,62 \%$ & $31,81 \%$ & $32,66 \%$ & $22,58 \%$ & $17,64 \%$ & $16,40 \%$ & $4,17 \%$ & $2,28 \%$ & $12,80 \%$ \\
\hline $15^{\circ} \mathrm{C}-18^{\circ} \mathrm{C}$ & Desconforto por resfriamento & - & - & - & - & $5,65 \%$ & $25,42 \%$ & $13,58 \%$ & $13,98 \%$ & $2,92 \%$ & $1,34 \%$ & $0,97 \%$ & - & $5,33 \%$ \\
\hline $11^{\circ} \mathrm{C}-15^{\circ} \mathrm{C}$ & Resfriamento elevado & - & - & - & - & $0,27 \%$ & $4,17 \%$ & $2,42 \%$ & $0,54 \%$ & - & - & - & - & $0,61 \%$ \\
\hline \multicolumn{2}{|r|}{ Horas não calculadas (TE) } & $8,06 \%$ & $5,46 \%$ & - & - & - & - & - & - & - & $4,30 \%$ & $8,06 \%$ & $8,06 \%$ & $2,82 \%$ \\
\hline \multicolumn{2}{|r|}{ Total de horas no mês } & 744 & 696 & 744 & 720 & 744 & 720 & 744 & 744 & 720 & 744 & 720 & 744 & 8784 \\
\hline
\end{tabular}

Fonte: Alerta Rio (2016). Organização: LEMOS E OSCAR JÚNIOR (2017).

Os períodos sazonais contrastantes de 2016 tomados como base foram verão e inverno (Tabela III). Ressalta-se que das 2.155 horas do verão, 5,48\% não tiveram horas calculadas de TE. Enquanto, todas as horas do inverno que compreende um total de 2.221 foram calculadas.

Fica evidenciado um verão com presença de altos índices de conforto, distribuídos nas faixas de stress térmico $(4,97 \%)$, desconforto por aquecimento $(26,08 \%)$ e leve desconforto $(45,01 \%)$ e com apenas $18,47 \%$ das suas horas na zona de neutralidade. Totaliza-se, assim, um desconforto de 76,06\%. No inverno, ocorreu predomínio de 48,22\% das horas classificadas na zona de neutralidade. Contudo, este valor é superado pelo somatório das faixas de desconforto ao calor $(14,02 \%)$ com a de desconforto ao frio $(37,75 \%)$. Nota-se aqui um domínio do não calor com $85,97 \%$.

Tabela III - Classificação da porcentagem de horas do verão e inverno nas classes de conforto térmico.

\begin{tabular}{c|c|c|c|}
\hline Intervalo do ID $\left({ }^{\circ} \mathrm{C}\right)$ & Níveis de conforto térmico & Verão & Inverno \\
\hline$>30^{\circ} \mathrm{C}$ & Stress térmico & $4,97 \%$ & - \\
$27^{\circ} \mathrm{C}-30^{\circ} \mathrm{C}$ & Desconforto por aquecimento & $26,08 \%$ & $2,20 \%$ \\
$24^{\circ} \mathrm{C}-27^{\circ} \mathrm{C}$ & Leve desconforto & $45,01 \%$ & $11,82 \%$ \\
$20^{\circ} \mathrm{C}-24^{\circ} \mathrm{C}$ & Zona de conforto ou neutralidade térmica & $18,47 \%$ & $48,22 \%$ \\
$18^{\circ} \mathrm{C}-20^{\circ} \mathrm{C}$ & Leve desconforto & - & $24,40 \%$ \\
$15^{\circ} \mathrm{C}-18^{\circ} \mathrm{C}$ & Desconforto por resfriamento & - & $12,36 \%$ \\
$111^{\circ} \mathrm{C}-15^{\circ} \mathrm{C}$ & Resfriamento elevado & - & $0,99 \%$ \\
\hline \multicolumn{2}{r|}{ Horas não calculadas (TE) } & $5,48 \%$ & - \\
\hline \multicolumn{2}{r|}{ TOTAL DE HORAS NOS PERioDOS SAZONAIS } \\
\hline
\end{tabular}

Fonte: Alerta Rio (2016). Organização: LEMOS E OSCAR JÚNIOR (2017).

Refinando mais a investigação, nos períodos matutino (05:00 às 12:00), vespertino (13:00 às 18:00), noturno (19:00 às 04:00), os meses de maio, agosto, setembro, outubro e novembro foram os que tiveram ao longo dos períodos do dia as maiores porcentagens de horas na zona de conforto ou neutralidade térmica, ou seja, apresentaram um total de dias mais confortáveis. Enquanto janeiro, manteve-se com o predomínio de TE no leve desconforto durante a manhã, tarde e noite. Junho e julho configuraram alterações: os períodos matutinos e vespertinos encontraram-se predominantemente com a porcentagem de horas na zona de conforto ou neutralidade e os período noturno configuraram-se mais frios, com a 


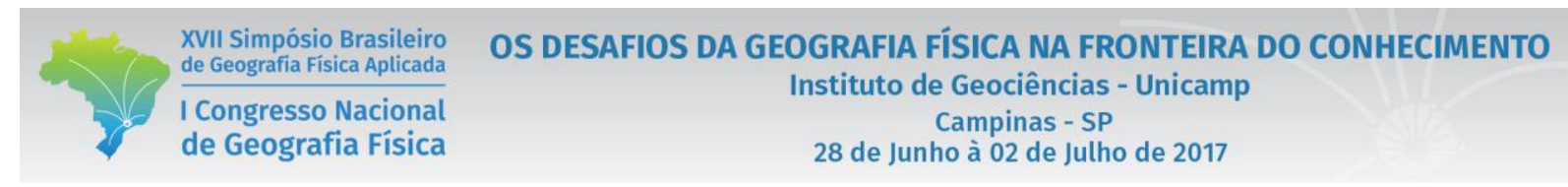

classe de conforto desconforto por resfriamento $(37,67 \%)$ e leve desconforto $(41,61 \%)$, respectivamente. Já fevereiro, março, abril e dezembro intercalaram com manhãs nas classes desconforto por aquecimento e leve descoforto, enquanto as tardes mantiveram-se um pouco mais críticas, com as horas na faixa desconforto por aquecimento, e as noite com leve desconforto.

Na tabela IV, o perído de 05:00 às 12:00 apresenta um total de horas de desconforto ao calor de 47,51\%, zona de conforto $36,27 \%$ e desconforto ao frio de $16,23 \%$. No período vespertino $56,05 \%, 34,24 \%$ e 9,7\%, respectivamente. Das 19:00 às 04:00 observa-se os registros de 26,83\%, 40,22\% e 26,17\%. Nota-se que a tarde é o único período do dia que o não calor não predomina sobre o calor, fisicamente explicado a partir do balanço radioativo.

Tabela IV - Classificação do total da porcentagem de horas do período do dia na classe de conforto térmico.

\begin{tabular}{|c|c|c|c|c|c|}
\hline \multirow{10}{*}{ TOTAL } & Intervalo do ID $\left({ }^{\circ} \mathrm{C}\right)$ & Níveis de conforto térmico & Manhã (05:00-12:00) & Tarde (13:00-18:00) & Noite (19:00-04:00) \\
\hline & $>30^{\circ} \mathrm{C}$ & Stress térmico & $1.64 \%$ & $3.64 \%$ & - \\
\hline & $27^{\circ} \mathrm{C}-30^{\circ} \mathrm{C}$ & Desconforto por aquecimento & $18.00 \%$ & $24.68 \%$ & $1.26 \%$ \\
\hline & $24^{\circ} \mathrm{C}-27^{\circ} \mathrm{C}$ & Leve desconforto & $27.87 \%$ & $27.73 \%$ & $25.57 \%$ \\
\hline & $20^{\circ} \mathrm{C}-24^{\circ} \mathrm{C}$ & Zona de conforto ou neutralidade térmica & $36.27 \%$ & $34.24 \%$ & $40.22 \%$ \\
\hline & $18^{\circ} \mathrm{C}-20^{\circ} \mathrm{C}$ & Leve desconforto & $10.35 \%$ & $8.47 \%$ & $17.32 \%$ \\
\hline & $15^{\circ} \mathrm{C}-18^{\circ} \mathrm{C}$ & Desconforto por resfriamento & $5.09 \%$ & $1.23 \%$ & $7.98 \%$ \\
\hline & $11^{\circ} \mathrm{C}-15^{\circ} \mathrm{C}$ & Resfriamento elevado & $0.79 \%$ & - & $0.87 \%$ \\
\hline & \multicolumn{2}{|c|}{ Horas não calculadas (TE) } & - & - & $6.78 \%$ \\
\hline & \multicolumn{2}{|c|}{ TOTAL DE HORAS NO PERIODO } & 2928 & 2196 & 3660 \\
\hline
\end{tabular}

Fonte: Alerta Rio (2016). Organização: LEMOS E OSCAR JÚNIOR (2017).

\subsection{Percepção da população e frequentadores do bairro}

Os questionários, outro instrumento utilizado para a análise do conforto térmico em Bangu, levantaram informações referente à população, ao bairro, problemas ambientais, sensação térmica e questões estruturais das casas dos moradores. Dentre os 89 entrevistados, 36\% estão na faixa etária de 15-24 anos, $26 \%$ na $25-39,27 \%$ na $40-59$ e $11 \%$ são maiores que 60.

Quando perguntados sobre quantas horas em média passam no bairro, $51 \%$ das pessoas responderam que permanecem entre 12-24 horas, $25 \%$ entre 10-12 horas, $17 \%$ entre 8-10 horas e apenas 7\% dos entrevistados passam menos que 8 horas. Os tempos de permanência estão diretamente relacionados com a relação da população com o bairro, que varia, conforme representada pela figura 2. Importante destacar que aproximadamente 70,79\% dos entrevistados residem em Bangu.

Segundo a população, as temperaturas elevadas, o excesso de lixo e a poluição sonora são os principais problemas urbanos presentes no bairro, como demonstra a figura 3. Demais problemas são mencionados também, porém com menor frequência. Investigando, então, a percepção sobre a sensação térmica da população banguense e frequentadores, $48 \%$ classificaram a temperatura do bairro como muito desconfortável, 43\% consideraram desconfortável e 8\% confortável (Figura 4). Nenhuma pessoa considerou o bairro como muito confortável. 
Campinas - SP

28 de Junho à 02 de Julho de 2017

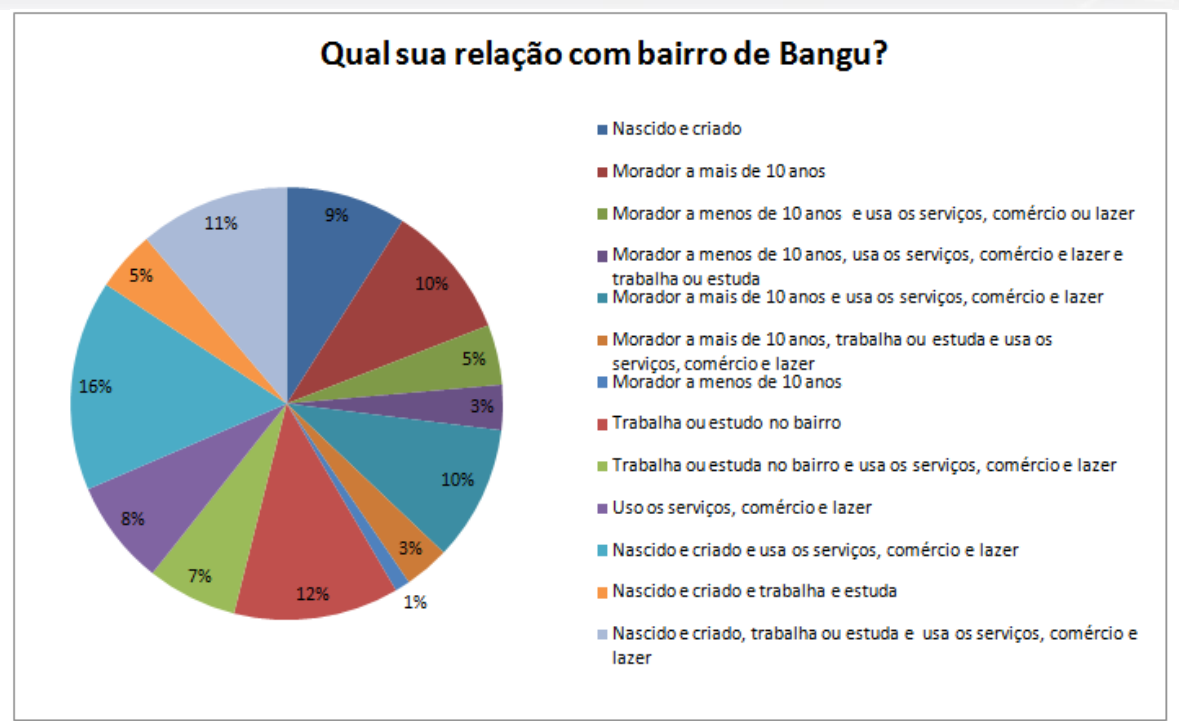

Figura 2 - Relação da população entrevistada com Bangu.

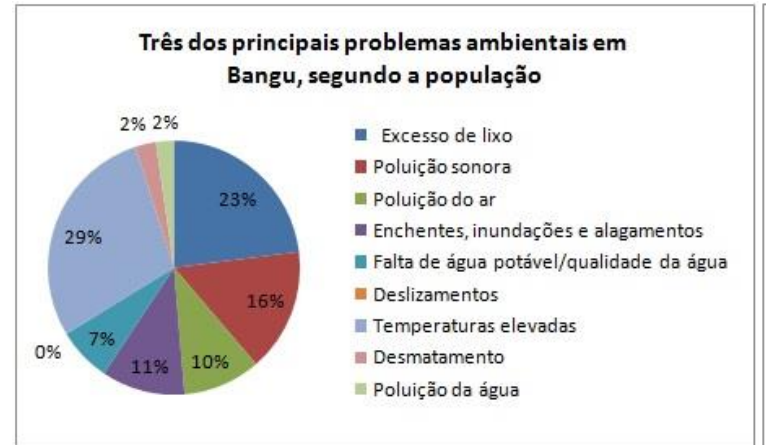

Figura 3 - Principais problemas ambientais.

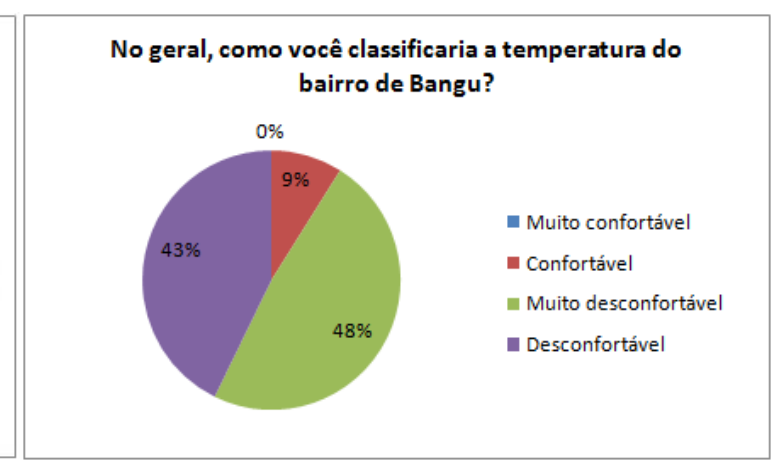

Figura 4 - Classificação da temperatura.

A situação térmica do bairro para $51 \%$ dos entrevistados é prejudicial à saúde e qualidade de vida, para $13 \%$ aos negócios e $12 \%$ à ambos. Enquanto $24 \%$ considera que a situação não interfere em nada para a população. Como mostra as figuras 5 e 6, os entrevistados relataram também quais locais seriam os mais desconfortáveis e confortáveis em termos de temperatura.

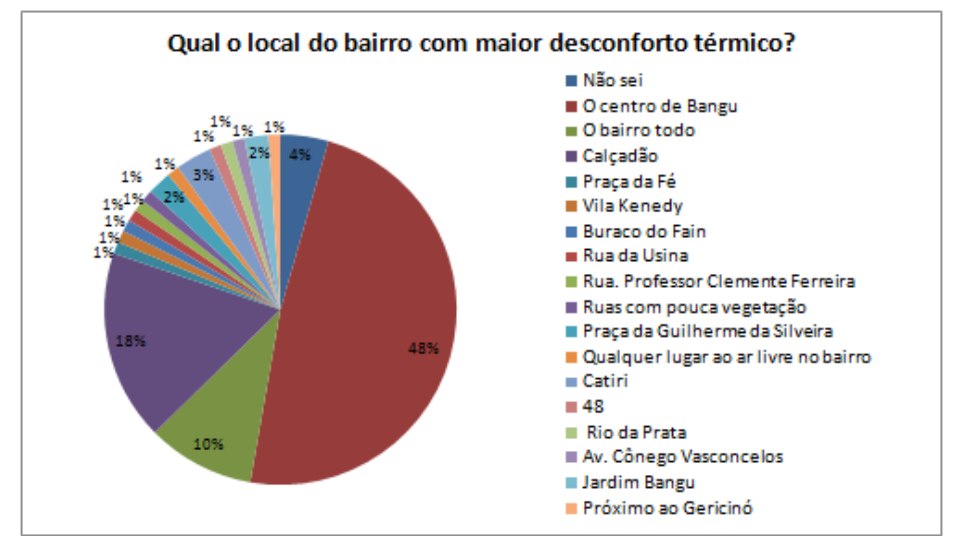

Figura 5 - Locais com maiores desconforto em termos de temperatura. 


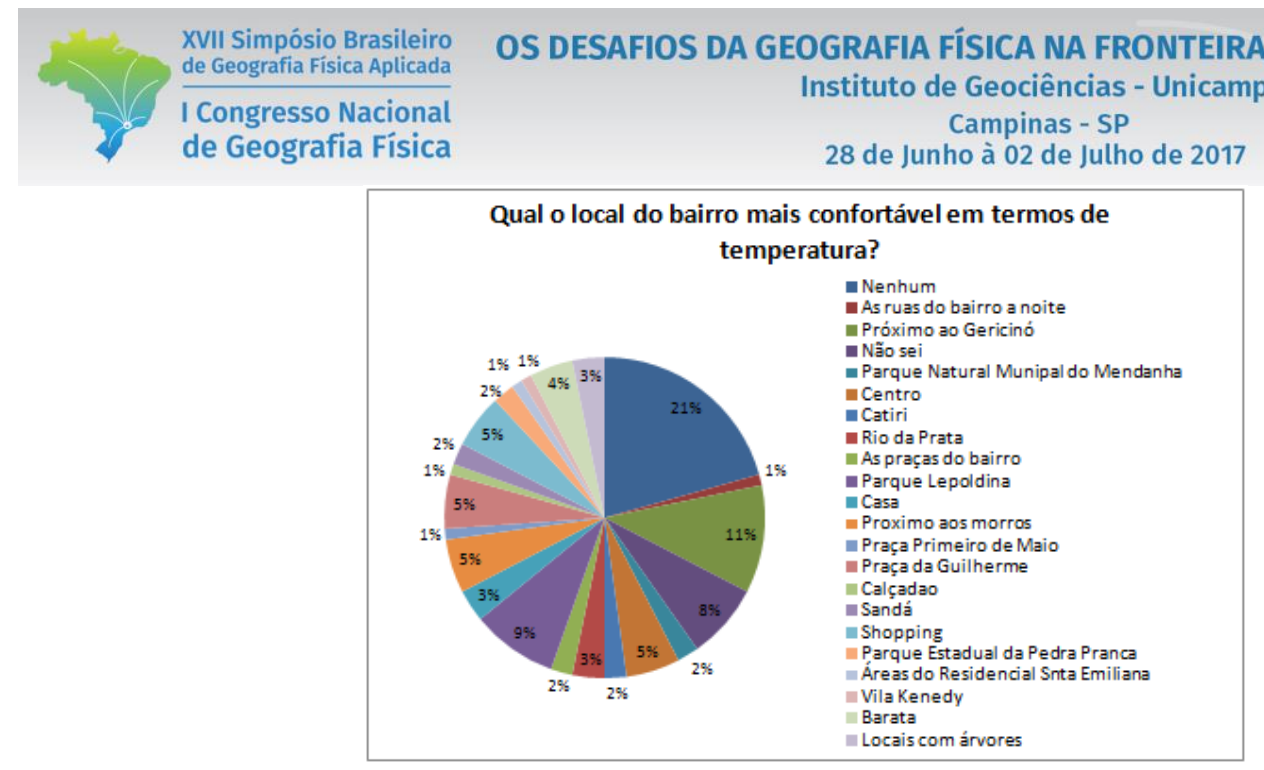

Figura 6 - Locais com maiores conforto em termos de temperatura.

Predominantemente, o centro do bairro, área de comércios e serviços que predomina intenso fluxos de pessoas e veículos, apareceu entre as respostas dos entrevistados com 48\%, seguido do calçadão de Bangu (localiza-se no próprio centro) com $18 \%$ como sendo as áreas mais desconfortáveis. Nesse sentido, as respotas convergiram com as áreas indicadas por Lemos e Oscar Júnior (2016) de maiores temperaturas da superfície e menores NDVI. O bairro todo também foi citado por 10\%. Entre os mais confortáveis, nenhum lugar do bairro (21\%), próximo ao maciço do Gerininó (11\%) e o Parque Lepoldina (8\%) predominaram. As áreas próximas ao pé das serras de Bangu e do Mendanha, com árvores, o Parque Natural Municipal do Mendanha e o Parque Estadual da Pedra Branca embora em menores quantidades também foram destacadas pela população por apresentarem vegetação, indicando a percepção desta sobre a importância das áreas verdes na regulação térmica. Já o sub-bairro do Barata que também foi elencado como confortável não se localiza dentro da delimitação territoral de Bangu.

Investigando sobre as estruturas das casas das 63 pessoas que residem no bairro, destacam-se: $41 \%$ das coberturas das residências de laje cimentada, 19\% são de telhas de amianto e $14 \%$ de telhas de barro. Entre os quintais 55\% são todo cimentado, 16\% são cimentado e arborizado e 9\% não possuem quintal. Os tipos de estruras predominantes são responsáveis por maiores estocagem de energia, alterando o balanço de energia e hídrico, favorecendo o desconforto térmico.

Quando perguntados sobre os espaços verdes existentes no bairro, 74\% sentem falta por haver poucos espaços. Outros $15 \%$ não sentem falta por considerarem haver muitos espaços, $8 \%$ não souberam responder e $3 \%$ afirmaram não existir espaços verdes no bairro (Figura 7).

A população afirma que sobre a atuação do poder público na melhoria do conforto e da qualidade ambiental do bairro que não existem intervenções (42\%), que até existem, mas são poucas (26\%) citando como exemplos obras de sanemento básico, coleta de lixos, plantio de árvores e mudas nas serras e nas 
praças do bairro e o vaporizador de água, fazendo menção ao sistema de refrigeração ${ }^{6}$ instalado em 2002 pela prefeitura no calçadão de Bangu. Não souberam responder $20 \%$ e $4 \%$ responderam que existem sim intervenções do poder público, mencionando algumas das já citadas anteriormente.

Por outro lado, chama a atenção que $69 \%$ dos entrevistados desconhecem os parâmetro urbanísticos que o Plano Diretor (PD) define para o bairro e $13 \%$ afirmam que nunca tiveram curiosidade, demonstrando uma baixa participação popular no ordenamento e gestão urbana. Dizem conhecer superficialmente 15\%, enquanto uma ínfima parcela da população diz conhecer e sempre consultar o Plano Diretor (3\%) (Figura $8)$.

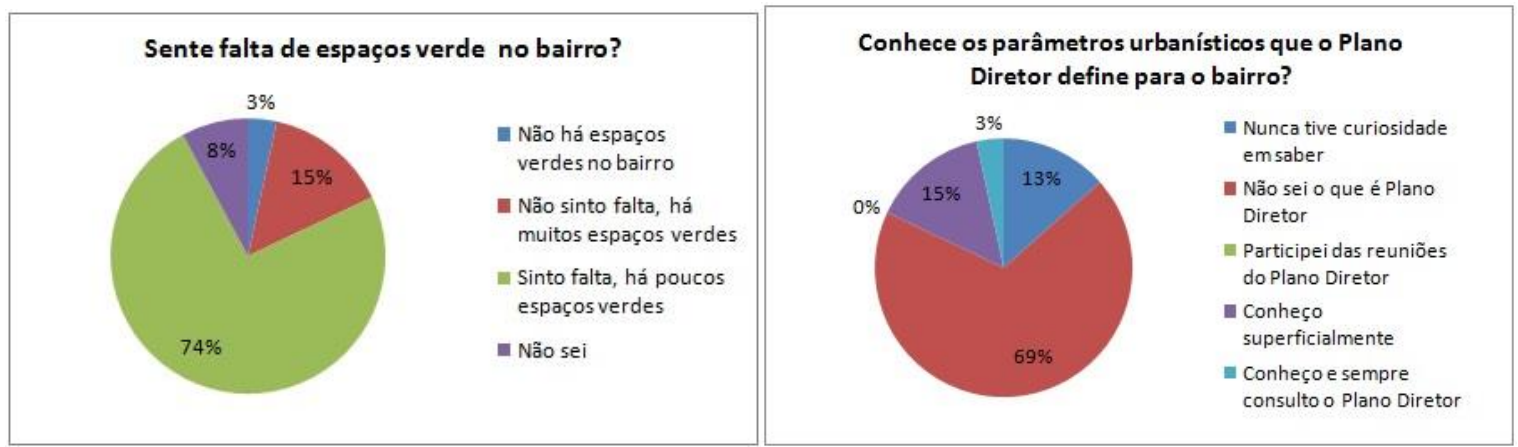

Figura 7 - Relação da população com os espaços verdes. Figura 8 - Conhecimento da população sobre o PD.

\section{Considerações finais}

Analisando o conforto térmico para o bairro Bangu no ano de 2016, o trabalho constatou que mesmo que a quantidade de horas predomine na zona de conforto ou neutralidade $(37,40 \%)$, a situação final das porcentagens de desconforto ao calor somado ao desconforto ao frio prevalecem sobre o conforto $(59,78 \%)$. O mesmo acontece para o período sazonal de inverno e para os período matutino, vespertinos e noturnos. Isto demonstra que o bairro apresenta questões a serem resolvidas para minimizar o desconforto, sobretudo para enfrentar o verão, cujo somatório das classes de leve desconforto $(45,01 \%)$, desconforto por aquecimento $(26,08 \%)$ e stress térmico $(4,97 \%)$ alcançam $76,06 \%$, e igualmente para enfrentamento no período vespertino (que apresentou-se com o somatório de $56,05 \%$ de desconforto ao calor). O verão e o período da tarde foram os únicos em que o não calor não superou o calor.

Deve-se enfatizar que pelos registros meteorológicos, quando da ocorrência da maior quantidade de horas dos TEs fora da zona de conforto ou netralidade, como no verão, o predomínio esteve na classe leve desconforto em 2016. Portanto, os mesmos diferenciam-se da percepção subjetiva do conforto térmico da

\footnotetext{
${ }^{6}$ Primeira estrutura de refrigeração de uma viação pública no país inaugurada em 2002 durante a gestão do prefeito César Maia.
} 
população banguense e frequentadores, pois segundo os questionários aplicados, a maioria da população considerou a temperatura do bairro muito desconfortável (48\%). Ressalta-se que a percepção subjetiva do conforto não possui um consenso. Isto deve-se as diferenças fisiológicas, por isso quando aplicado os questinários, as respostas sobre a classificação da temperatura do bairro variaram, sendo tomada como base as que predominaram.

A investigação em Bangu demonstrou também que o bairro que tem a fama de ser um dos mais quentes do Município do Rio de Janeiro, apresentou prevalência de um não calor anual (porcentagem de horas na zona de conforto somadas as classes leve desconforto, desconforto por resfriamento e resfriamento elevado) de 56,14\% sobre o calor (as classes de desconforto ao calor - 41,04\%). Assim, com as TEs obtidas questionasse: seria Bangu realmente um dos bairros mais quentes da cidade do Rio de Janeiro ou teríamos no bairro uma "tradição inventada"?

Segundo Hobsbawm e Ranger (1984), por "tradição inventada" entende-se um conjunto de práticas, normalmente reguladas por regras tácitas ou abertamente aceitas (inclui-se tanto as tradições inventadas, construídas e formalmente institucionalizadas, mas também as que surgiram de forma difícil de se localizar, estabelecendo-se com rapidez), tais práticas rituais ou simbólicas, visam inculcar certos valores e normas de comportamento através de repetição, o que implica, automaticamente, uma continuidade em relação ao passado. A pesquisa, possui limitação para tal afirmação, mas indícios nessa linha. No entanto, trata-se de uma hipótese que necessita ser testada, pois a amostra de dados utilizada é inferior a 30 anos. Além disso, a estação meteorológica do bairro foi desativada, não contando com registro in locu.

De toda forma, a estratégia metodológica dos questionários e dos registros meteorológicos evidenciaram que para resolução da problemática em Bangu, devem ser considerados os sistemas atmosféricos locais (que conferem uma sucetibilidade natural a elevadas temperaturas), o planejamento urbano para o bairro (que assim como os demais localizados na zona oeste mostra-se ineficiente) e a percepção da população, uma vez que esta é afetada pelo clima. O planejamento ineficiente converte-se no adensamento das casas, no aumento da massa concrética e na redução das áreas verdes, favorecendo o desconforto. A carência de vegetação retratada pelos entrevistados, traduz-se na necessidade do verde.

O conforto térmico deve ser práxis no planejamento urbano, pois é um dos parâmetros fundamentais para a manutenção da qualidade de vida. Devido ao avanço das áreas urbanas, vêm intensificando-se em decorrência da alteração dos padrões da superfície, sendo necessária a participação da sociedade no ordenamento e gestão urbana, cobrando um planejamento eficiente. O Plano Diretor é um instrumento para cobrar do poder público, minimizando tais problemáticas e proporcionando melhorias para o bairro. Entretanto, o questionário demonstrou que a política urbana é desconhecida ou ignorada pela população. 


\section{Bibliografia}

CORREA, R. L. Meio ambiente e a metrópole. In: ABREU. M. A. Natureza e Sociedade do Rio de Janeiro. Rio de Janeiro. Biblioteca Carioca. p.27-36. 1992.

GOBO, J.P. A.; GALVANI, E. Inserção do estudo da dinâmica atmosférica regional na análise dos padrões de conforto térmico humano no Rio Grande do Sul: estudo de caso em Santa Maria - RS. Geousp-Espaço e Tempo(Online), v. 19, n. 3, p. 564-584.. 2016.

FARIAS, H. S.; BRANDÃO; A. M. P. M. O campo térmico com indicador de qualidade ambiental para políticas públicas:estudo de caso do bairro Maracanã/RJ.Encontro Nacional da Associação Nacional de PósGraduação e Pesquisa em ambiente e sociedade. Brasília/DF, 23 a 26 de maio de 2006.

FERRARO, L. W.; HASNACK, H.; PORTO, M. L. O clima local em ambientes alterados: aplicações ao conforto térmico em Charqueadas, RS. Boletim Gaúcho de Geografia, 20: 156, dez., 1995. Versão online disponível em: <http://seer.ufrgs.br/bgg/article/view/38204/24586>. Acessado em 20 de dezembro de 2016.

HOBSBAWM, E; RANGER,T. (orgs). A invenção das tradições. Rio de Janeiro. Paz e Terra, p. 9-23. 1984. Disponível em: <http://www.janduarte.com.br/textos/teoria/invencao_tradicoes.pdf>. Acessado em 24 de fevereiro de 2016.

INSTITUTO BRASILEIRO DE GEOGRAFIA E ESTATÍSTICA. Geociências. Acessado em: <http://downloads.ibge.gov.br/downloads_geociencias.htm>. Acessado em 24 de fevereiro de 2016.

INSTITUTO DE ASTRONOMIA, GEOFÍSICA E CIÊNCIA ATMOSFÉRICA. Início das estações do ano. <http://www.iag.usp.br/astronomia/inicio-das-estacoes-do-ano>. Acesso em 13 de fevereiro de 2017.

LEMOS, L.O.; OSCAR JÚNIOR. Proposta metodológica para seleção de áreas amostrais em estudo do subcanal termodinâmico: estudo de caso das ilhas de calor no bairro de Bangu (RJ). Simpósio Brasileiro de Climatologia Geográfica. Goiânia/GO, 25 a 29 de outrubro de 2016.

O GLOBO PAY. Sistema de refrigeração de Bangu apresenta problemas. <https://globoplay.globo.com/v/2969437/>. Acesso em 15 de fevereiro de 2017.

SANTOS, R. L. S.; ANDRADE, H. O. de. Avaliação quantitativa do conforto térmico de uma cidade em área de transição climática: Feira de Santana-Bahia, Brasil. Revista de Geografia Norte Grande, 40: 77-84 (2008).

SILVA, L. P. da.; AMORIM, M. C. de C. T. O conforto térmico em Presidente Prudente - SP: uma análise do ano de 2008 e das salas de aula da FCT/UNESP. Disponível em:< http://agbpp.dominiotemporario.com/doc/CPG32A-7.pdf>. Acessado em 20 de dezembro de 2016.

SISTEMA ALERTA RIO DA PREFEITURA DO RIO DE JANEIRO. Dados meteorológicos. Disponível em: <http://alertario.rio.rj.gov.br/download/dados-meteorologicos/> . Acesso em 03 de fevereiro de 2017.

SOUZA, Débora M. de.; NERY, J. T. O Conforto térmico na perspectiva da Climatologia Geográfica. Geografia (Londrina), v. 21, n.2. p.65-83, maio/ago. 2012. 